Localizador: 19057 doi: $10.35366 / 93979$

\title{
Secuenciación de nueva generación: utilidad en dermatología
}

\author{
Next generation sequencing: use in dermatology \\ Sandra Pinedo-Donelli,* Elizabeth Ball ${ }^{\ddagger}$
}

Palabras clave: Secuenciación de nueva generación, dermatosis, genodermatosis, cáncer de piel.

Keywords:

Next-generation

sequencing

skin diseases,

genodermatosis, skin

cancer.

\author{
* Especialista en \\ Dermatología. Hospital \\ Universitario de Caracas. \\ ${ }^{\star}$ Especialista en \\ Dermatología. Adjunto del \\ Servicio de Dermatología \\ del Hospital Universitario de \\ Caracas.
}

Universidad Central de Venezuela. Caracas, Venezuela.

Conflicto de intereses:

Ninguno.

Recibido: 03/Noviembre/2019.

Aceptado:

22/Diciembre/2019.

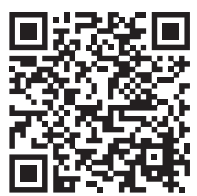

\section{RESUMEN}

En el año 2001 se obtuvo el primer «borrador» del genoma humano, creado al utilizar un método llamado secuenciación de Sanger, que consistía en la identificación del orden o secuencia de las bases nitrogenadas dentro de la molécula de ADN. Por tratarse de un método engorroso y complicado la secuenciación del genoma tardó aproximadamente 10 años y el costo fue muy elevado. Esto llevó a los investigadores a desarrollar nuevas técnicas que hicieran posible conocer la naturaleza de la molécula de ADN de múltiples genes y organismos de manera rápida y a menor costo. Su finalidad era poder determinar las alteraciones genéticas o mutaciones que dan origen a enfermedades y permitir conocer la identidad de un determinado organismo a través de su genoma. Por ejemplo, en el caso de las epidemias que son causadas por un agente desconocido, al descifrar la secuencia de los nucleótidos que integran su ADN podría conocerse la identidad del agente causal, al comparar los datos obtenidos con un genoma de referencia. Es así como surge la secuenciación de nueva generación como un método que logra secuenciar múltiples fragmentos de ADN en tiempo real y en paralelo, a fin de descifrar el genoma de un determinado organismo o determinar los genes responsables de una enfermedad en un tiempo muy corto. Son múltiples los usos que se le dan a esta técnica en dermatología, por ejemplo, para decidir conductas terapéuticas, predecir el pronóstico y la respuesta al tratamiento en enfermedades malignas e inflamatorias de la piel, entre otros.

\section{ABSTRACT}

In 2001 the first draft of the human genome was created using a method called Sanger sequencing, which is based on the identification of the order or sequence of the nitrogenous bases within the DNA molecule. Because it was a complicated method, the genome sequencing took approximately 10 years and the cost was very high. This led to researchers developing new techniques that made it possible to know the nature of the DNA molecule of multiple genes and organisms quickly and at a lower cost. Its purpose was to be able to determine the genetic alterations or mutations that give rise to diseases and allow to know the identity of a certain organism through its genome. For example, in the case of epidemics that are caused by an unknown agent, deciphering the sequence of the nucleotides that integrate their DNA could reveal their identity, when comparing the data obtained with a reference genome. This is how new generation sequencing emerges as a method that manages to sequence multiple DNA fragments in real time and simultaneously in order to decipher the genome of a given organism or to sequence the genes responsible for a disease in a very short time. There are many uses of this technique in dermatology, for example, to choose the most appropriate treatment, predict the prognosis and therapeutic response in malignant and inflammatory skin diseases, among many others.

\section{INTRODUCCIÓN}

$\mathrm{E}$ I material genético de los organismos eucariotas está formado por la molécula de doble hélice de ácido desoxirribonucleico (ADN) que se compone de cuatro bases nitrogenadas: adenina, guanina, citosina y tiamina, las cuales constituyen la doble cadena de ADN. Cada gen tiene a los pares de bases (PB) agrupados en diversas combinaciones y longitudes. La totalidad de genes de un organismo representa el genoma. ${ }^{1}$
El Proyecto Genoma Humano (PGH) permitió crear mapas genéticos con la localización exacta de los genes dentro de los cromosomas. En el año 2001 se obtuvo el primer borrador del genoma humano mediante el método de secuenciación de Sanger, basado en la identificación de la secuencia de las bases nitrogenadas. Por ser un procedimiento engorroso, los investigadores desarrollaron nuevas técnicas llamadas «secuenciación de nueva generación» (SNG) para conocer la naturaleza del ADN en múltiples organismos de manera rápida y a 
menor costo. Su objetivo era determinar las mutaciones que dan origen a enfermedades y conocer la identidad de organismos a través de su genoma. ${ }^{2}$

La SNG surge como un método para secuenciar múltiples fragmentos de ADN en tiempo real y en simultáneo. La potencial implicación de esta técnica en la práctica clínica hace necesario su conocimiento.

\section{El Proyecto Genoma Humano y la secuenciación de Sanger}

En el año 2003 se completó el PGH. Su objetivo era conocer la secuencia u orden exacto de los nucleótidos del ADN. Este trabajo inició en 1990, liderado por el National Institute of Health. Sólo fueron secuenciadas las áreas eucromáticas (92\% de la molécula de ADN). No fueron estudiadas las áreas heterocromáticas (8\% restante), conformadas por centrómeros y telómeros. La secuencia molde del genoma humano fue resultado del análisis de varias moléculas de ADN provenientes de múltiples donantes. El PGH reveló la existencia de 20,500 genes y dio a conocer su estructura, localización y función. ${ }^{1,3}$

La técnica de secuenciación se utiliza para conocer el orden exacto de los nucleótidos dentro de los genes. Los cromosomas humanos tienen aproximadamente 50,000300,000 pares de bases. El fundamento de esta técnica es que al conocer la identidad de una de las bases del par se puede conocer la de su complementaria. ${ }^{3}$ La secuenciación determina cuáles regiones de los cromosomas contienen genes y cuáles son las áreas no codificantes, cuya función es regular la transcripción y traducción del material genético. ${ }^{2}$

El método utilizado para el PGH fue la secuenciación de Sanger, creado por el bioquímico británico Frederick Sanger en 1977. Emplea fragmentos del ADN de 900 pares de base de longitud y los secuencia uno a la vez para luego ensamblarlos y formar secuencias más largas de ADN. ${ }^{2,4,5}$ Esta técnica requiere la elaboración de muchas copias de ADN. Se necesitan las siguientes condiciones para la replicación del ADN in vivo o in vitro mediante la reacción en cadena de polimerasa (PCR) (Figura 1):

\section{ADN polimerasa.}

2. «Primer» o cebador: fragmento pequeño de nucleótidos de una sola cadena que se une al ADN complementario y activa su transcripción.

3. Los cuatro desoxinucleótidos: adenina (dATP), guanina (dGTP), citosina (dCTP) y tiamina (dTTP).

4. El ADN a secuenciar (molde o plantilla).
5. Dideoxinucleótidos o versiones terminantes de los cuatro nucleótidos (ddATP, ddTTP, ddCTP, ddGTP). 4,6

Estos dideoxinucleótidos terminan la elongación de la cadena al carecer de un grupo 3'-OH, que es necesario para la formación del enlace fosfodiéster entre dos nucleótidos durante la síntesis de ADN. La incorporación de un dideoxinucleótido termina la secuenciación y produce varios fragmentos de ADN de longitud variable. Los dideoxinucleótidos se añaden a concentraciones lo bastante altas como para producir todas las posibles combinaciones de fragmentos $y$, al mismo tiempo, ser suficientes para realizar la secuenciación (Figura 1).²

El método consiste en combinar en una pipeta el ADN molde, la ADN polimerasa, el primer o cebador, los nucleótidos y los cuatro dideoxinucleótidos marcados con fluorescencia, estos últimos en menor cantidad que los nucleótidos normales. Esta preparación es sometida a altas temperaturas para desnaturalizar la molécula molde de ADN y así separar sus cadenas. Luego es enfriada para permitir la unión del cebador a cada una de las cadenas. Una vez unidos, la temperatura aumenta de nuevo para permitir que la ADN polimerasa sintetice el nuevo ADN, iniciando desde el cebador. La ADN polimerasa añadirá nucleótidos hasta que un dideoxinucleótido sea incluido en la cadena. A partir de este momento no pueden ser añadidos más nucleótidos y la cadena es terminada. Este proceso es repetido por varios ciclos. Cuando todos los ciclos son completados, cada uno de los dideoxinucleótidos han sido incorporados por lo menos una vez a la cadena de ADN. El final de cada fragmento de ADN está marcado por una molécula fluorescente (fluorocromo) asignado a cada nucleótido. Posteriormente, los fragmentos de ADN secuenciados son corridos a través de un tubo largo y delgado que contiene una matriz constituida por gel. Los fragmentos más cortos se mueven más rápido a través de los poros de la matriz que los fragmentos largos. ${ }^{7}$ En el momento en que cada fragmento pasa a través del final del tubo, es iluminado por un láser que detecta el color de la fluorescencia. De esta forma, la secuencia de la plantilla original de ADN es reconstruida (Figuras 1 y 2)..$^{2,4}$

El método de secuenciación de Sanger es altamente costoso, por lo que se emplea para secuenciar piezas pequeñas de ADN, como plásmidos bacterianos. Es poco eficiente para secuenciar genomas enteros grandes (metagenomas) porque no puede procesar varios fragmentos de la molécula de ADN en simultáneo. Para estos casos se emplean nuevas técnicas de secuenciación llamadas «secuenciación de nueva generación». ${ }^{4}$ 


\section{Secuenciación de nueva generación (SNG)}

Secuenciación de nueva generación (next-generation sequencing), secuenciación masiva paralela o profunda. Son términos relacionados que engloban tecnologías destinadas a la secuenciación masiva a gran escala de cualquier ácido nucleico en la actualidad. La SNG permite secuenciar el genoma humano en un día. ${ }^{8}$
Existe una variedad de plataformas de SNG que emplean distintas técnicas. Sin embargo, comparten un conjunto común de características que las distinguen de la secuenciación de Sanger y que implican múltiples ventajas: ${ }^{2}$

1. Paralelas: ocurren muchas reacciones de secuenciación al mismo tiempo, lo que permite la secuenciación

(a) Mezcla de reacción

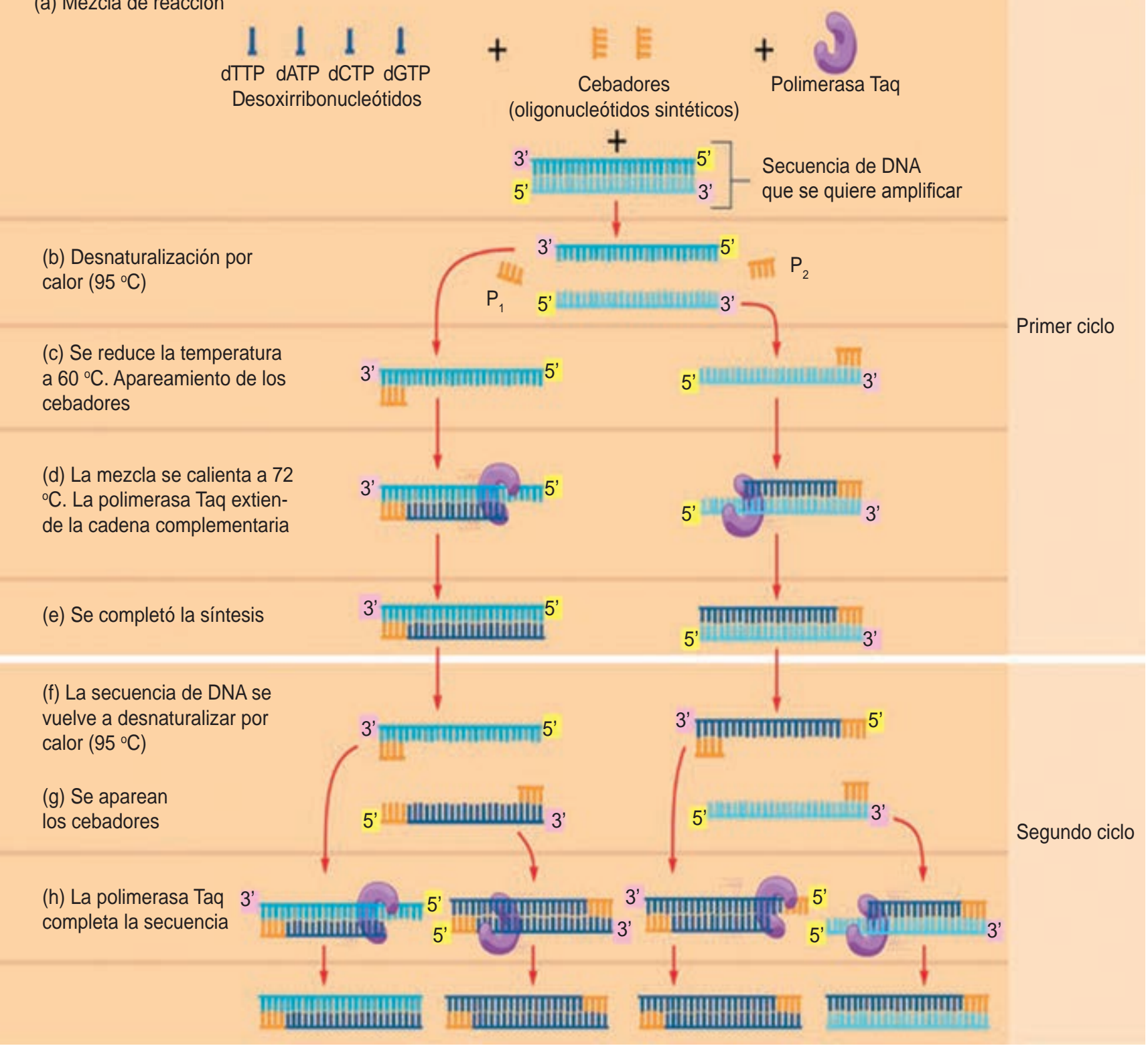

Figura 1: Técnica de la secuenciación de Sanger. 


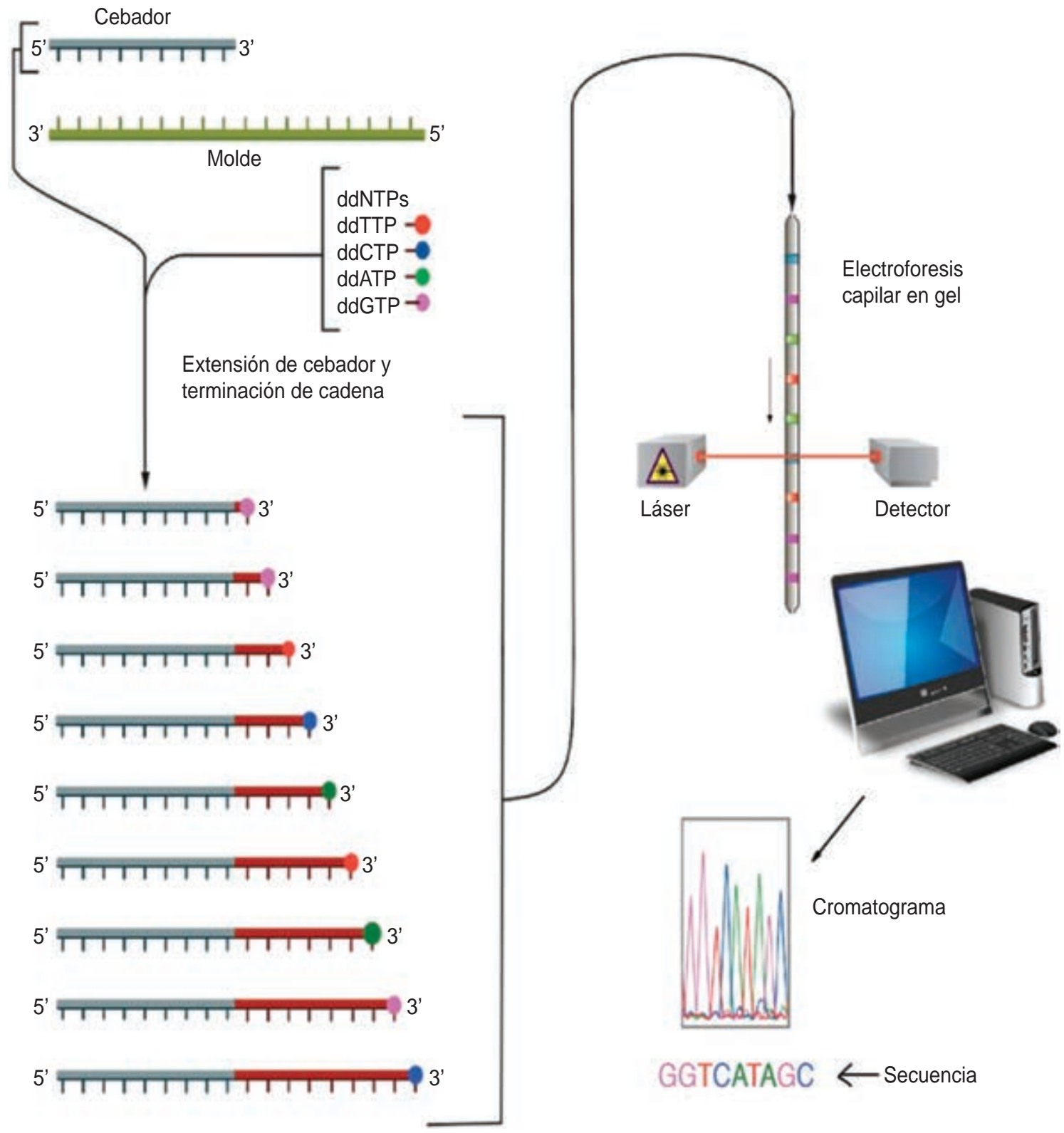

Figura 2: Método de lectura de las secuencias de Sanger.

simultánea y en tiempo real de múltiples plantillas de ADN.

2. Microescala: las reacciones son diminutas y se pueden hacer muchas a la vez en un chip. Los volúmenes de reactivos requeridos son muy pequeños.

3. Rápidas: puesto que las reacciones se realizan en paralelo, los resultados se obtienen mucho más rápido.
4. Bajo costo: secuenciar un genoma es más económico que con la secuenciación de Sanger. En 2001 el costo de la secuenciación del genoma humano fue de casi 100,000,000 \$ y en 2015 fue de 1,245 \$ gracias a la SNG.

5. Longitudes más cortas: típicamente, las lecturas se obtienen con fragmentos de 50 a 700 nucleótidos de longitud. 
Todas las técnicas de SNG hacen lecturas de millones de fragmentos pequeños de ADN en paralelo. Dichos fragmentos se unen y forman la secuencia completa. Cada uno de los tres billones de bases del genoma humano es secuenciado muchas veces, lo que aumenta la sensibilidad del procedimiento y permite identificar variaciones en el ADN. La SNG puede emplearse para estudiar todo el genoma o sólo áreas de interés como las áreas codificantes. ${ }^{4,8}$

Se requiere una «biblioteca» de ADN o genoteca que consiste en numerosos fragmentos de ADN de un organis- mo separados al azar a partir de una molécula madre. Estos fragmentos pueden comprender el genoma completo, exones, áreas promotoras del ADN o alelos de un gen. A cada fragmento se le añade un primer o cebador que activa la transcripción. Mediante técnicas de clonación por PCR se obtienen múltiples copias de cada fragmento, llamadas «amplicones»., 5,9

Los métodos de SNG se clasifican en dos: 1. Secuenciación de lectura corta y 2. Secuenciación de lectura larga de una sola molécula en tiempo real.5,6

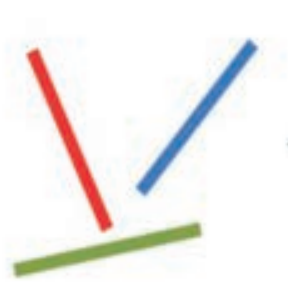

1. Fragmentos de ADN

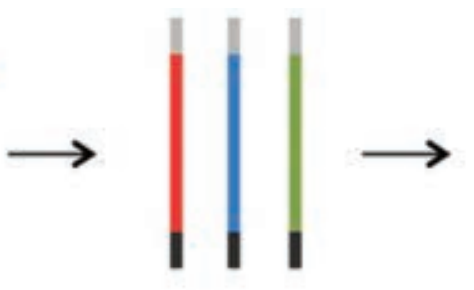

2. Unión a adaptadores

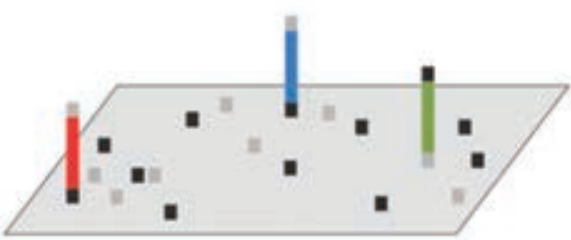

3. Fijación a pocillos

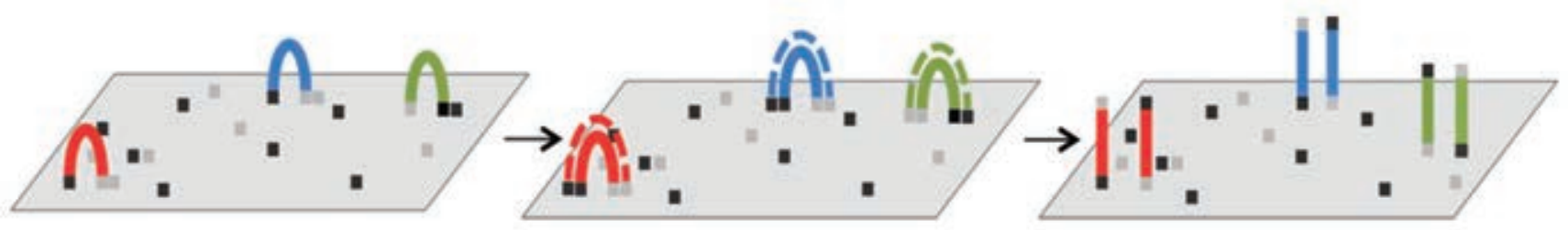

5. Amplificación por puentes de PCR

6. Extensión de los amplicones
4. Unión a los cebadores

7. Formación de múltiples amplicones

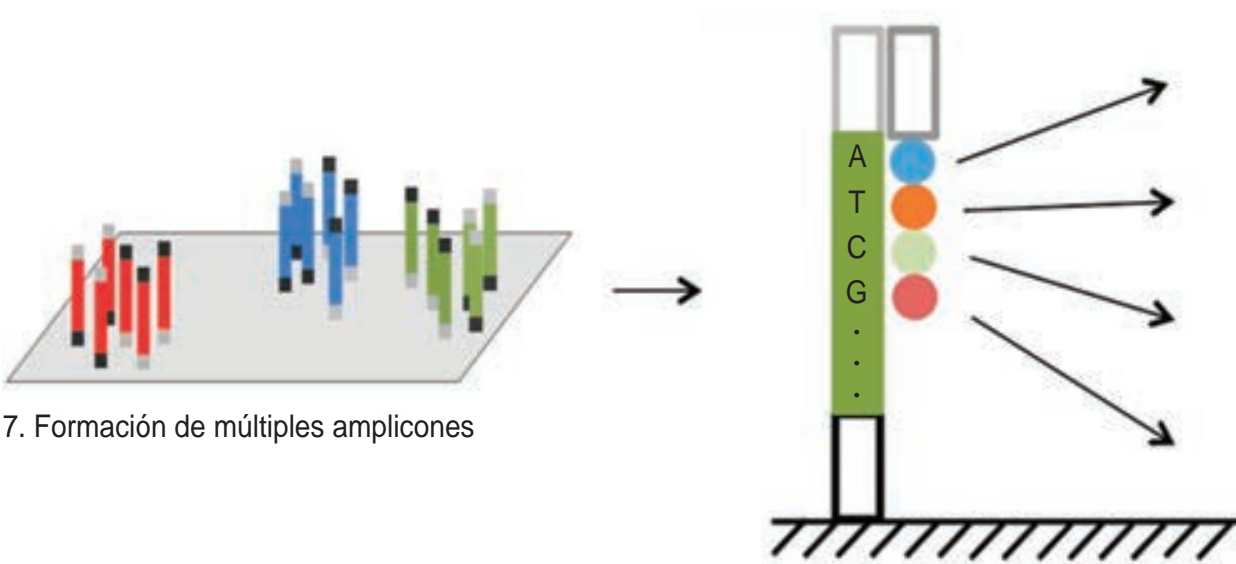

8. Incorporación de nucleótidos

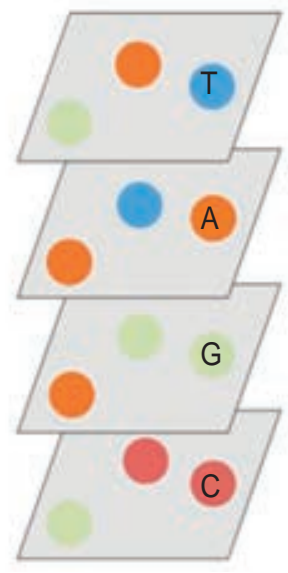

9. Múltiples secuenciaciones en paralelo

Figura 3: Pasos de la secuenciación en la plataforma Illumina. 


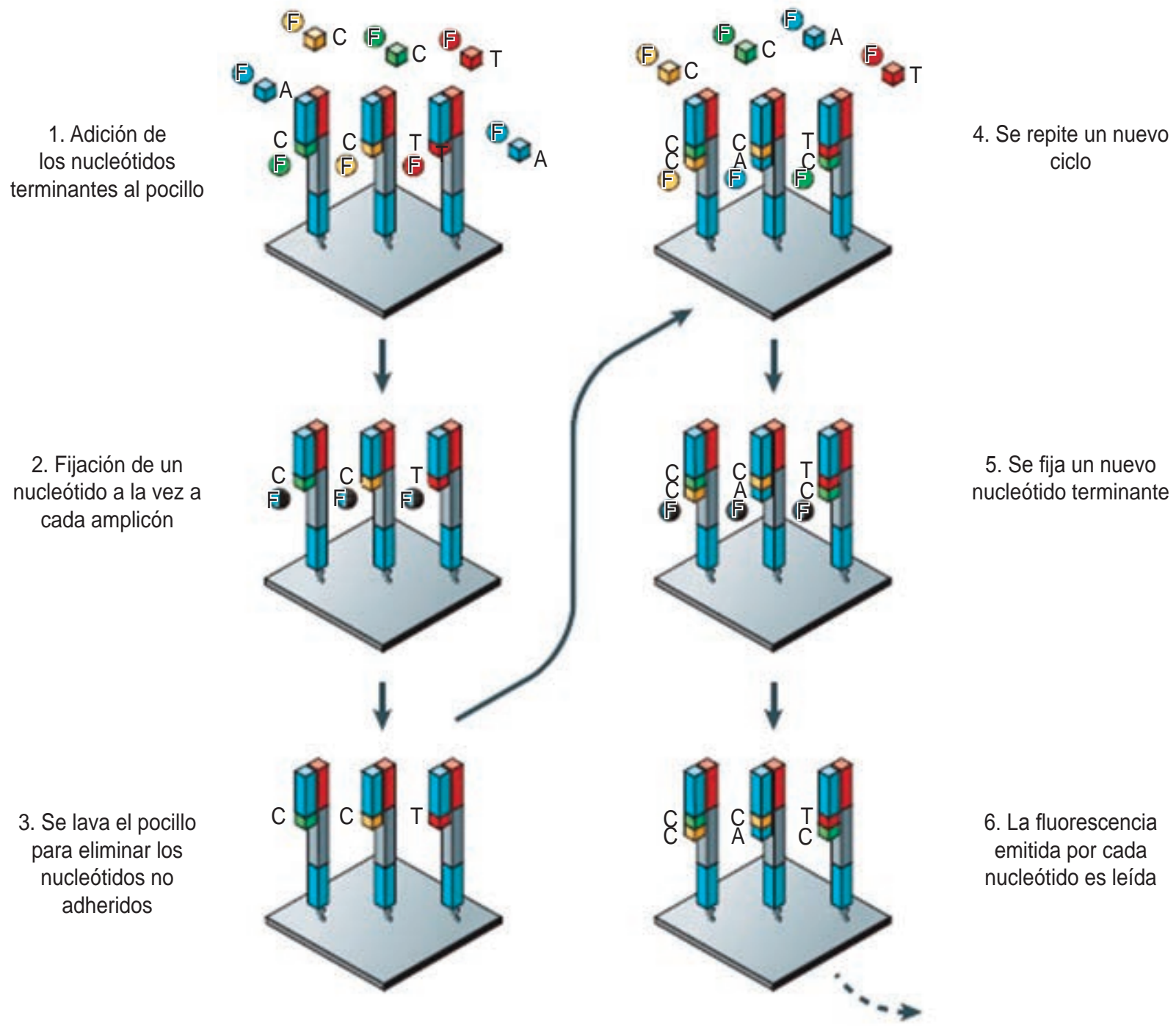

Figura 4: Método de adición de los nucleótidos terminantes en la plataforma Illumina.

\section{Secuenciación de lectura corta}

1.1. Plataforma Illumina (Solexa ${ }^{\circledR)}$ ): se utilizan análogos de cada nucleótido marcados con un fluorocromo que actúan como «terminadores reversibles» de la secuenciación. La amplificación de los fragmentos de ADN a secuenciar se hace por puentes de PCR. Cada fragmento se une a unos adaptadores en cada extremo, fijándose a una superficie sólida (pocillo) donde se unen al cebador, formando un puente y generando múltiples copias idénticas que son extendidas (Figura 3). En cada ciclo, los cuatro nucleótidos terminadores son añadidos al mismo pocillo con el ADN a secuenciar y son incorporados de uno en uno al fragmento por la ADN polimerasa. Una vez que cada nucleótido se ha unido al molde una vez, los restantes son lavados del pocillo para evitar que se unan en el mismo ciclo. Cuando se incorpora cada nucleótido terminante, es emitida una señal fluorescente detectada por un sistema. En la actualidad, esta plataforma es la más empleada en proyectos de secuenciación masiva. Esto se debe a su alta precisión, relación costo valor y la amplia disponibilidad de equipos en el mercado capaces de ejecutar esta técnica (Figura 4).5,6

1.2. Plataforma Roche 454: fue el primer equipo de SNG. La biblioteca de ADN está conformada por fragmentos de ADN unidos a adaptadores. Los amplicones son obtenidos por emulsión PCR en el que las moléculas individuales 
de $A D N$ se unen a microesferas y ocurre la clonación. Cada microesfera se cubre de amplicones que se inmovilizan para ser secuenciados y se adhieren a pocillos donde ocurre la secuenciación. Los cebadores se unen a los amplicones y garantizan su adecuada orientación. Las bases son incorporadas a los amplicones liberando una molécula de pirofosfato, proceso llamado «pirosecuenciación». El pirofosfato fluoresce y la cantidad liberada es directamente proporcional a la de los nucleótidos secuenciados. Esta reacción se produce en paralelo en un millón de pocillos y es detectada por una cámara sensible a fluorescencia (Figura 5).5,6

1.3. Plataforma Ion Torrent: se basa en la detección de protones $\left(\mathrm{H}^{+}\right)$liberados cuando los nucleótidos son incorporados al ADN. La plataforma contiene unos sen- sores que determinan cambios de voltaje directamente proporcionales y de $\mathrm{pH}$ inversamente proporcionales a la cantidad de protones. Los moldes de ADN se obtienen por emulsión PCR. Los nucleótidos son añadidos uno a uno por la polimerasa y se libera un $\mathrm{H}^{+}$al medio que es detectado y traducido en una señal computarizada que identifica al nucleótido añadido (Figura 6).5,6

\section{Secuenciación de lectura larga de una sola molécula en tiempo real}

2.1. Plataforma Pacific Biosciences: es una de las más nuevas, llamadas «plataformas de tercera generación».

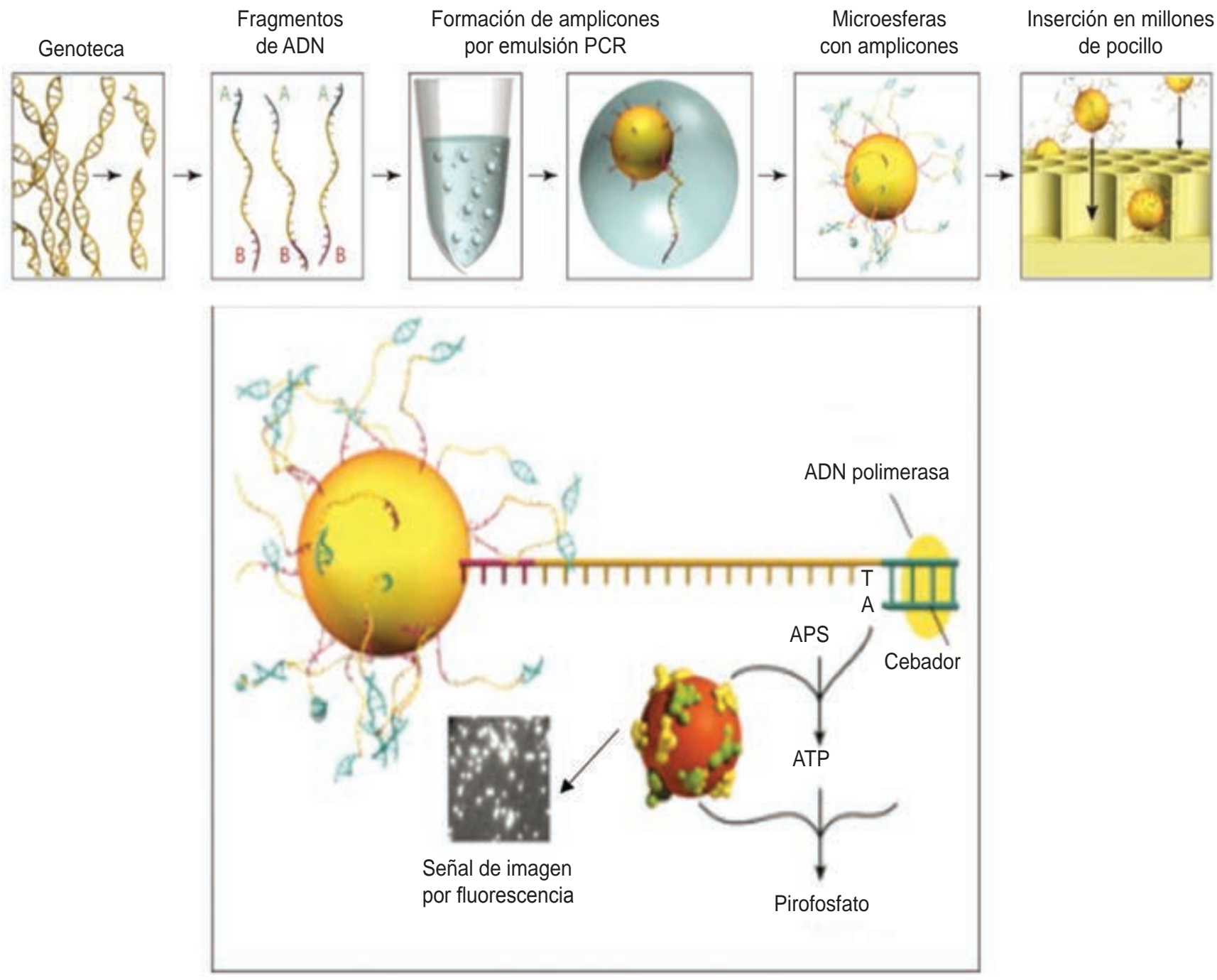

Figura 5: Pasos de la secuenciación en la plataforma ROCHE 454. 
Amplicones (emulsión PCR)
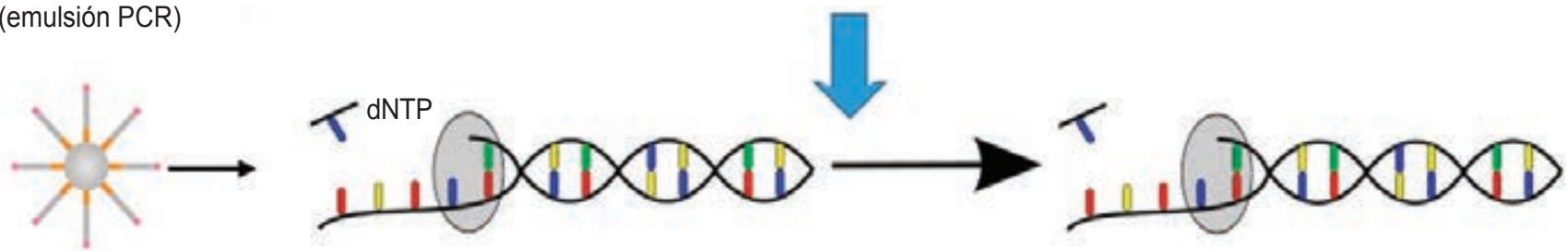

Si el nucleótido no complementa la plantilla, no se libera $\mathrm{H}^{+}$
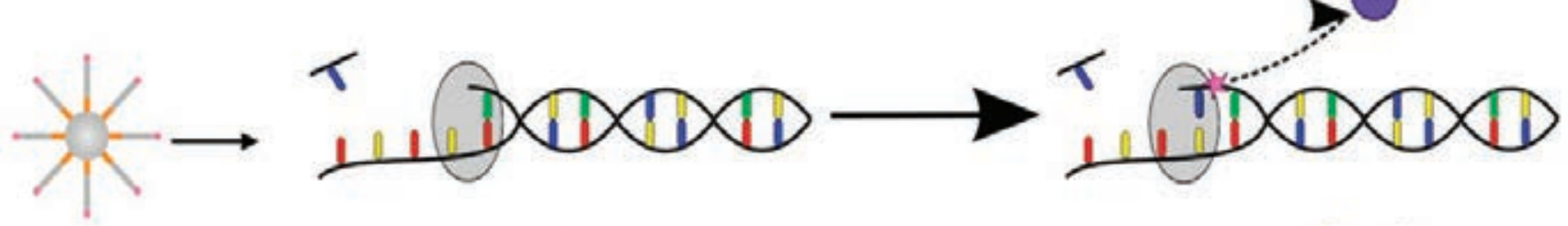

Si el nucleótido complementa la plantilla, se libera $\mathrm{H}^{+}$
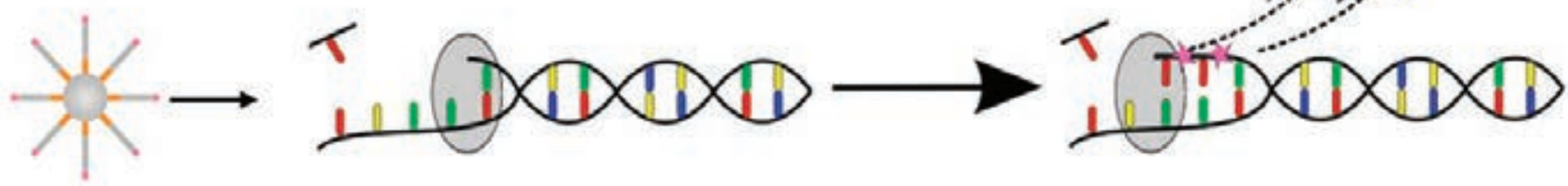

Si el nucleótido complementa varias bases seguidas, se liberan múltiples $\mathrm{H}^{+}$



Figura 6: Pasos de la secuenciación en la plataforma Ion Torrent.

Utilizan nanotecnología y no requieren reactivos. La ADN polimerasa se fija a los pocillos en vez de al molde de ADN y es capaz de secuenciar en tiempo real al ADN que se mueve a través de la enzima. Se llama «de una sola molécula» porque sólo se requiere la presencia de la polimerasa para la secuenciación. Cada vez que un nucleótido es incorporado, el grupo fosfato adherido a éste emite una señal fluorescente que es reconocida por unos nanosensores (Figura 7). 5,6

2.2. Plataforma de nanoporos Oxford: se utilizan nanosensores que forman un canal a través del cual pasa la plantilla de ADN. Se basa en el cambio de voltaje que ocurre entre uno y otro compartimiento al pasar cada nucleótido a través del canal. El cambio de voltaje es traducido en una señal que, de acuerdo a su intensidad, permite identificar cada nucleótido. Utiliza una sola plantilla de ADN sin necesidad de clonarla, con lo cual se obtiene rápidamente las secuencias (Figura 8).5,6

\section{Usos de la SNG en la práctica clínica}

\subsection{Detectar en una molécula de ADN diferentes mu- taciones puntuales, tales como (Figura 9):}

- Sustituciones: el cambio de una base nitrogenada por otra.

- Deleciones: pérdida de un fragmento de ADN. Puede comprometer una base, exones o genes completos.

- Inserciones: introducción de nucleótidos adicionales.

- Rearreglos cromosómicos como inversiones (cambio de sentido de un fragmento cromosómico que rota $180^{\circ}$ ) o traslocaciones (desplazamiento de un segmento cromosómico dentro del mismo cromosoma o a otro).

El método de Sanger sólo reconoce sustituciones, deleciones e inserciones pequeñas. La SNG permite evaluar todas las mutaciones realizando un solo estudio. ${ }^{8}$ 
3.2. Identificar el genoma de microorganismos patógenos: ampliando el conocimiento acerca de su patogenicidad, sensibilidad a medicamentos e identificación de gérmenes relacionados con epidemias. ${ }^{8}$ Un ejemplo contundente fue la identificación de una cepa virulenta de E. coli $(\mathrm{O} 104: \mathrm{H} 4)$ previamente desconocida como causante de un epidemia de síndrome disenteriforme en Alemania en 2011 y relacionada con síndrome hemolítico urémico. ${ }^{10}$

3.3. Utilidad en oncología: la SNG puede evaluar todos los oncogenes participantes en el desarrollo de distintas neoplasias. Esto implica un aumento en la sensibilidad diagnóstica, en la estimación más exacta del pronóstico, en la precisión en el estadiaje y en el conocimiento de la sensibilidad a drogas. ${ }^{8}$
Las células neoplásicas poseen heterogeneidad del genoma. En el cáncer existen múltiples poblaciones celulares con diversos rearreglos genéticos y en continua división celular. El análisis de estas células mediante SNG permite conocer cuáles son las mutaciones asociadas a cáncer. Cada neoplasia tiene mutaciones específicas identificables que permiten dirigir el tratamiento, evaluar la resistencia a los fármacos y sus mecanismos fisiopatológicos. En la actualidad existe un proyecto en desarrollo por el Consorcio Internacional del Genoma del Cáncer (ICGC, por sus siglas en inglés) que evalúa los cambios del genoma en varias neoplasias comparándolas con pares de tejido normal. ${ }^{11}$ En 2003, Ley y colaboradores realizaron los primeros estudios de cáncer con SNG. Utilizaron 140 muestras de pacientes con leucemia mieloide aguda y descubrieron

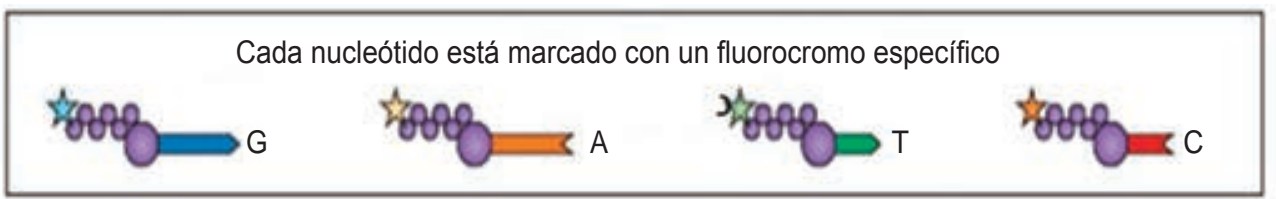

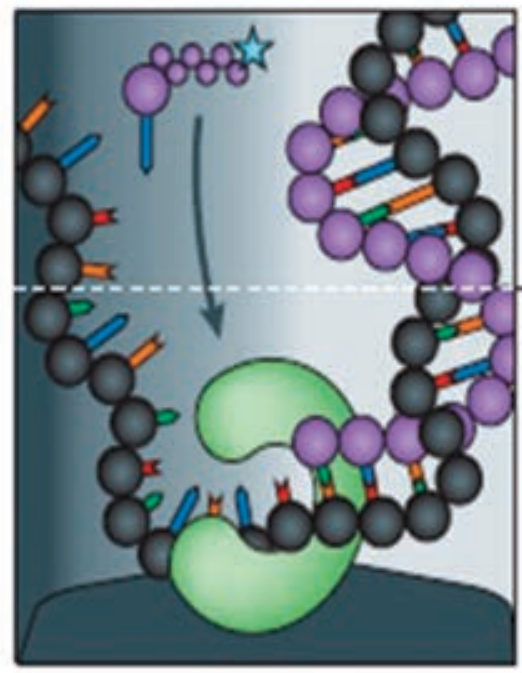

1. ADN polimerasa adherida a millones de pocillos secuencia una cadena de ADN
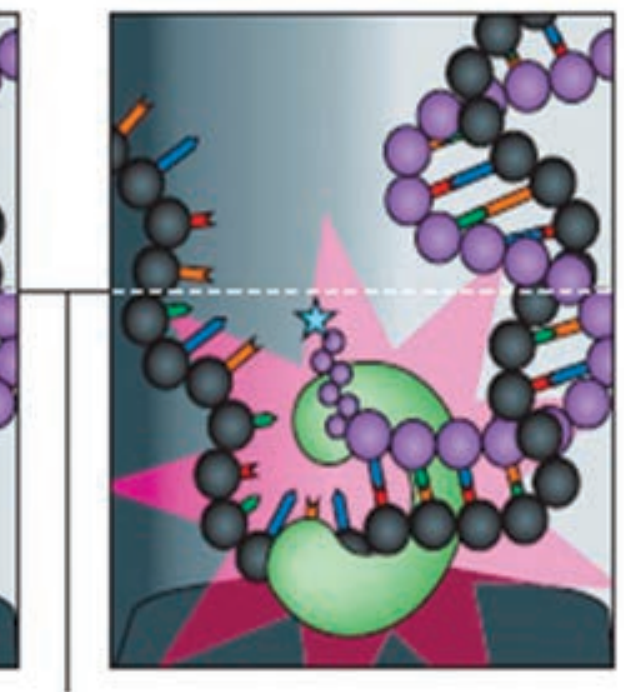

2. Se emite una fluorescencia cada vez que se añade un nucleótido a la cadena

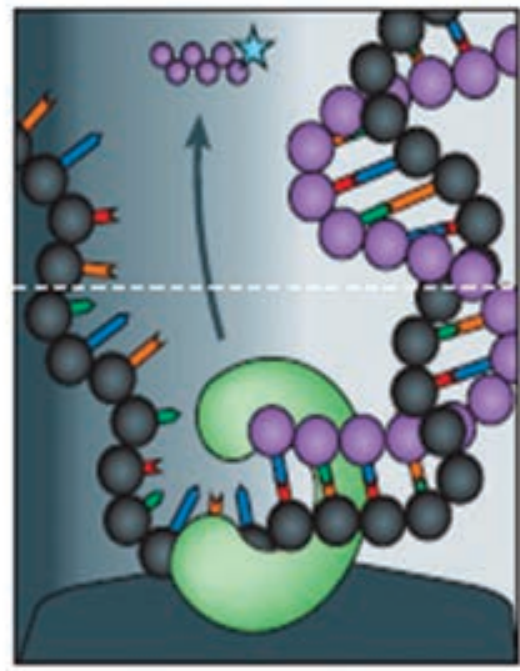

3. Se traduce en una señal que es captada por una cámara
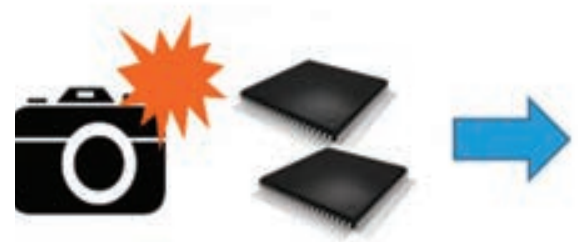

4. Señal reconocida por unos nanosensores

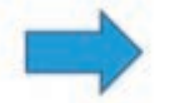

5. Identificación del nucleótido añadido

Figura 7: Pasos de la secuenciación en la plataforma Pacific Biosciences. 


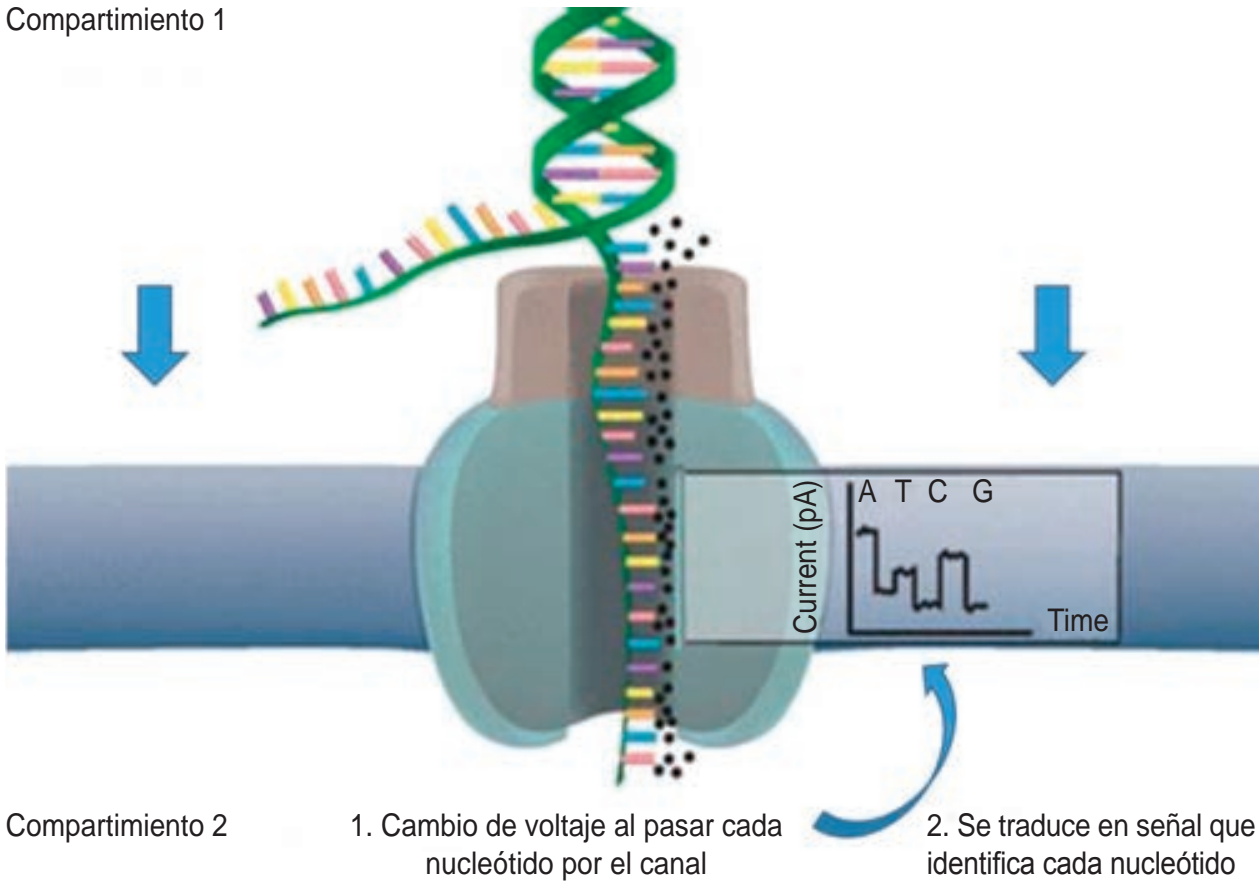

Figura 8:

Pasos de la secuenciación en la plataforma de nanoporos Oxford. siete mutaciones nuevas no descritas importantes para el diagnóstico de esta enfermedad. ${ }^{12}$

3.4 Análisis prenatal: es otro de los usos de la SNG. Tiene una alta sensibilidad. El ADN que proviene de células fetales en la circulación materna es secuenciado, leído y mapeado en el genoma humano de referencia. Si existe una mutación se identificará el cromosoma afectado. ${ }^{11}$

Los datos obtenidos mediante SNG se analizan en cuatro pasos. Se compara la secuencia de ADN obtenida con un genoma de referencia que contiene los genes a estudiar (panel de genes). La alteración en los nucleótidos es identificada y se filtra de acuerdo a unos criterios, que incluyen la frecuencia de aparición de la mutación en la población, efectos deletéreos en la síntesis de proteínas o las funciones del ARNm y la relación con fenotipos patológicos. . $^{9,11,12}$

La limitación más importante de la SNG es la interpretación de las alteraciones genéticas encontradas y su relación con los fenotipos clínicos. Una mutación puede ser o no patológica dependiendo del contexto. Existen múltiples mutaciones deletéreas que son toleradas y no se asocian a manifestaciones clínicas si no existen estímulos desencadenantes o si hay moléculas que contrarresten su expresión. Al contrario, es posible que una alteración fenotípica se relacione al mismo tiempo con múltiples mutaciones y que haya mutaciones cuya expresión fenotípica ocurre en la adultez o con penetrancia incompleta. Esta técnica debe ser utilizada de manera cuidadosa por las implicaciones sobre el consejo genético. ${ }^{9}$

A pesar de las continuas mejoras en la SNG, la tasa de errores es elevada. Existen áreas del genoma que aún no han podido secuenciarse y otras que están secuenciadas de manera errónea. Por esta razón, los métodos de SNG no han sido totalmente validados en la práctica clínica. Otro impedimento es la ausencia de infraestructura y software adecuado para el almacenamiento de la información generada. ${ }^{9}$ La SNG ha identificado genes previamente no conocidos causantes de enfermedades o síndromes no descritos y enfermedades huérfanas o poco frecuentes. Además, otra de las limitaciones es que puede reconocer cientos de variaciones de una determinada secuencia sin que tenga necesariamente implicación clínica. En estos casos es muy difícil identificar cuál es la secuencia responsable de una determinada enfermedad. ${ }^{13,14}$

\section{Secuenciación de nueva generación en Dermatología}

En los últimos cinco años la SNG ha cobrado interés en la investigación dermatológica porque ha permitido conocer las bases genéticas y moleculares de la biología cutánea. También ha permitido comprender mejor la fisiopatología de múltiples dermatosis. ${ }^{9}$ 
Para su aplicabilidad clínica la SNG se basa en dos técnicas: la secuenciación completa de exomas (SCE) y la secuenciación del genoma completo (SGC). Los exomas son las partes del ADN conformadas por exones o partes codificantes que se transcriben a ARNm maduro. Cada nucleótido es secuenciado por lo menos 100 veces y la lectura es archivada en un software para su comparación con una secuencia prototipo que no tiene mutaciones. Al existir varias secuencias que representan múltiples variantes de un mismo exón es difícil comparar todas estas secuencias con la secuencia prototipo y, más aún, traducir estos descubrimientos en fenotipos clínicos. La SNG es una técnica de análisis molecular mejorada en la identificación de genes no caracterizados y de locus alterados en enfermedades comunes como psoriasis, dermatitis atópica y carcinoma basocelular. ${ }^{15}$

4.1. Enfermedades hereditarias y genodermatosis: uno de los mayores usos de la SCE es el descubrimiento de nuevos genes que han permitido la identificación de más de 20 genodermatosis con manifestaciones clínicas variables y otras desconocidas. Algunos ejemplos incluyen la identificación de mutaciones somáticas en los oncogenes HRAS y KRAS en el síndrome del nevo sebáceo, así como el descubrimiento de una nueva enfermedad autosómica recesiva epitelial secundaria a mutaciones germinales del receptor del factor de crecimiento epidérmico. ${ }^{15}$

Los pacientes con genodermatosis representan retos diagnósticos. En muchas de estas enfermedades el diagnóstico clínico puede ser difícil debido a que las manifestaciones clínicas son proteiformes. Los avances en SNG cambiaron el paradigma diagnóstico. En un estudio doble ciego realizado por Takeichi y colaboradores, se aplicó SCE a pacientes con genodermatosis de diagnóstico desconocido y lesiones cutáneas inespecíficas. Mediante esta técnica se demostró que, aunque las lesiones eran
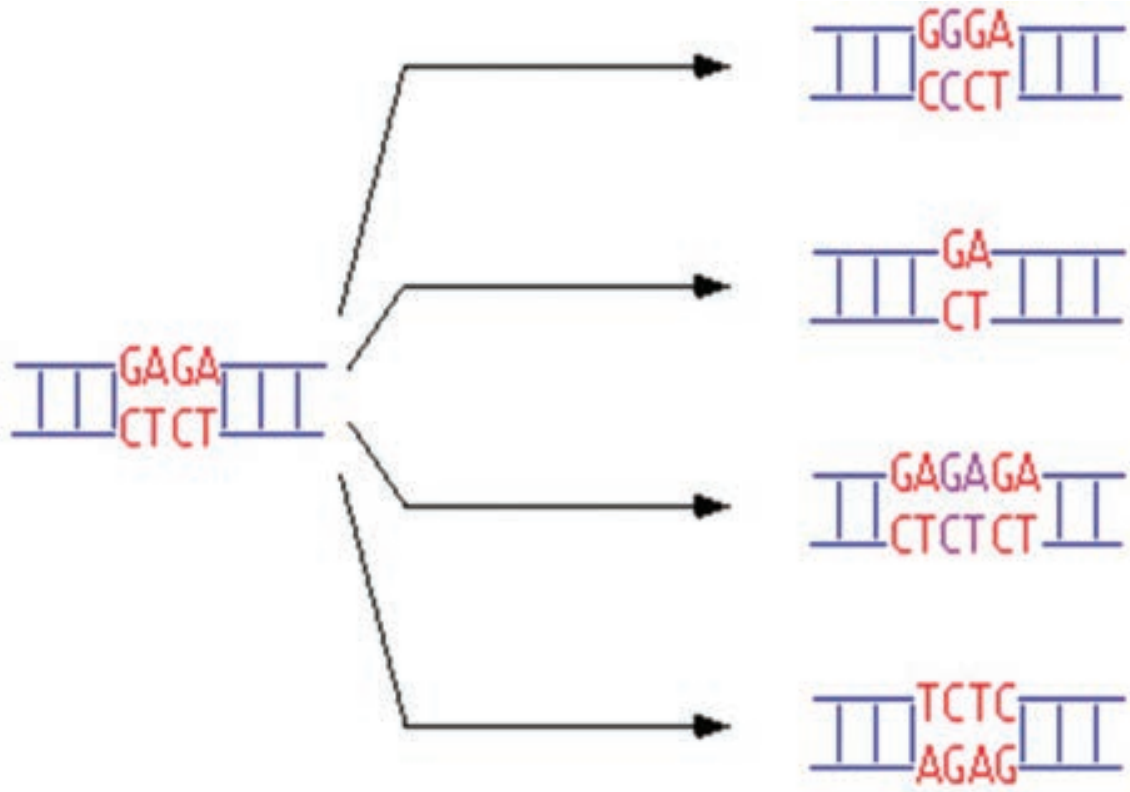

Sustitución: cambio de una base por otra

Deleción: pérdida de uno o más nucleótidos

Inserción: agregación de nucleótidos

Inversión: cambio de sentido de un fragmento cromosómico (gira 180)

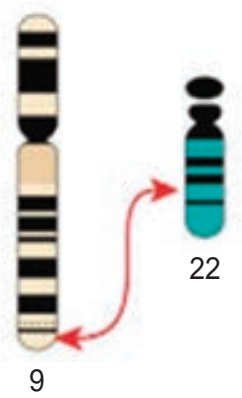

Traslocación: desplazamiento de un segmento cromosómico dentro del mismo cromosoma o a otro

Figura 9: Tipos de mutaciones puntuales detectadas por secuenciación de nueva generación. 
similares en muchos, el diagnóstico molecular fue diferente entre ellos, correspondiendo las mutaciones encontradas a acrodermatitis enteropática, displasia ectodérmica hipohidrótica, epidermólisis ampollar distrófica, entre otros. ${ }^{16,17}$

4.2. Melanoma maligno (MM): el melanoma cutáneo tiene una de las más altas tasas de mutaciones, con un promedio de 17 mutaciones $/ 10^{6} .{ }^{12} \mathrm{Al}$ menos $75 \%$ de los MM tienen alteraciones en sus pares de bases consistentes con daños producidos por radiaciones UV. Dentro de los genes afectados se incluyen BRAF, NRAS, MAP2K1, PTEN y CDKN2A. ${ }^{18}$

Mediante SNG se determinó que las mutaciones del gen BRAF aparecen en el $40-70 \%$ de los MM. El BRAF puede ser bloqueado por inhibidores de cinasa como el Vemurafenib o el Dabrafenib. Ihle y colaboradores evaluaron las ventajas de la SNG para determinar las mutaciones del BRAF y plantearon que pronto sustituiría a los otros métodos en el análisis molecular. ${ }^{19}$

No existen actualmente plataformas de SNG aprobadas para el análisis del melanoma. ${ }^{20,21}$ En 2016 Watson y colegas realizaron una clasificación basada en múltiples estudios a gran escala de hechos con SNG. ${ }^{18}$ De 40 a 50\% de los MM que carecen de la mutación BRAF poseen mutaciones en NF1. Hoy en día, el melanoma se clasifica en cuatro subgrupos: BRAF+, RAS+, NF1+ (con ausencia de mutaciones en BRAF y RAS) y los de triple tipo salvaje (TTS). Los pacientes con el subtipo NF1 son de mayor edad al momento de la aparición del MM. Los de TTS presentan sólo 30\% de las alteraciones asociadas con radiación UV en comparación con otros subtipos. ${ }^{22,23}$

La clasificación genómica del MM fue hecha con la finalidad de un tratamiento dirigido. El descubrimiento de mutaciones en NF1 hace que sean susceptibles a inhibidores de la MAP-cinasa. Sin embargo, no todos los que poseen esta alteración responden al tratamiento. Algunos tienen mutaciones concomitantes de la vía del PD-1. Los inhibidores de la tirosin-quinasa son efectivos en los MM de TTS que presentan una alta tasa de mutaciones del receptor $\mathrm{C}-\mathrm{KIT}{ }^{18}$

Uno de los descubrimientos más importantes hechos con la SCE fue la identificación de mutaciones del gen TP53, más frecuentes en los melanomas cutáneos que en los mucosos. Esta mutación parece también determinar la aparición del MM en cabeza y cuello. Esto implicaría una relación entre las radiaciones UV y las mutaciones TP53 con base en la localización del tumor. ${ }^{19,24}$

En un estudio realizado por Curtin y colegas se determinó que los melanomas pueden presentar alteración en el número de copias de ADN. Estos tumores tienen inserciones en los cromosomas 7, 8 y deleciones en el
10. Los que son secundarios a fotoexposición tienen inserciones en los cromosomas 13, 22 y deleciones en los cromosomas 3, 6, 8 y 13 . Se demostró que el periodo libre de enfermedad se asocia con el total de deleciones e inserciones cromosómicas. ${ }^{25}$

En los últimos años la inmunoterapia que emplea inhibidores de los receptores PD-1 y CTLA- 4 ha tenido un gran impacto en el tratamiento del melanoma. El Ipilimumab fue el primer medicamento aprobado para su uso en MM metastásico, ya que aumenta la supervivencia global hasta tres años, sobre todo en combinación con inhibidores del BRAF. ${ }^{26-28}$ Entre los factores que determinan la respuesta a inmunoterapia se encuentran: la carga mutacional, cantidad de transcriptomas implicados y presencia de linfocitos infiltrantes del tumor. La SNG ha sido utilizada para caracterizar estas células, las cuales son aisladas del huésped, clonadas in vitro y restituidas al paciente. Estos linfocitos destruyen el tumor y pueden producir regresiones completas en melanomas metastásicos..$^{29-32}$

4.3. Carcinoma basocelular (CBC): en 2015, Sand y su equipo analizaron los microARN (miARN) expresados en pacientes con CBC metastásico mediante SNG. Uno de los más frecuentes fue el Hsa-miR-301 b-3p, perteneciente a la familia del oncogén hsa-miR-130/301, que ha sido descrito en otros tipos de cáncer como promotor de invasión y metástasis. También hubo incremento de Hsa-miR-223$3 p$ y Hsa-miR-191-5p que estimulan la proliferación de queratinocitos senescentes mediante activación del factor Gli1, perpetuando su replicación. ${ }^{33-35}$

Aunque los inhibidores de la vía Hedgehog producen respuesta satisfactoria en los CBC metastásicos, existen tumores que desarrollan resistencia por mutaciones de novo en esta vía. Mediante SNG se demostró que pacientes con mutaciones del PTCH1 al inicio del tratamiento desarrollaban resistencia al Vismodegib por un aumento del número de copias de ADN del PTCH1. Se descubrieron también amplificaciones de los genes para PD-L1 y PD-L2, por lo que en la actualidad se plantea la posibilidad de administrar terapia anti-PD1 a pacientes con resistencia a los inhibidores de la $\mathrm{SHH} .{ }^{33}$

4.4. Carcinoma espinocelular (CEC): hoy en día no hay consenso sobre la opción terapéutica más adecuada para el tratamiento de los CEC metastásicos. Mediante estudios de SNG se determinó que $85 \%$ presenta mutaciones inactivadoras del gen supresor de tumores TP53. Además, existen drogas experimentales cuyo blanco es la proteína p53. ${ }^{36}$

Las alteraciones en el gen CDKN2A son frecuentes en los CEC. Este gen codifica dos proteínas supresoras: 
p14 y p16, que inhiben a la proteína estimuladora de la proliferación celular. Aquellos tumores con mutaciones en CDKN2A y pérdida de función de 16 podrían ser susceptibles a inhibidores de CDK4/6 como el palbociclib. ${ }^{36-38}$

La heterogeneidad genética se refiere a la diversidad de secuencias de ADN entre las células de un tumor único que pueden ser transferidas a la progenie por división celular. Incluyen mutaciones puntuales, alteraciones en el número de copias y traslocaciones intra o intercromosómicas. ${ }^{32}$ La forma más directa de evaluar la heterogeneidad intratumoral es comparando las secuencias de ADN entre diversas regiones del tumor. En el caso de los CEC ocurre que, a pesar de tener mutaciones definidas y establecidas, durante su evolución ciertos subclones celulares pueden presentar mutaciones adicionales, lo cual explicaría el porqué aparece resistencia a los medicamentos durante la evolución de la enfermedad. . $^{39,40}$

4.5. Psoriasis: mediante SNG se determinó que los pacientes con psoriasis tienen un mayor número de copias del locus para el receptor de linfocitos Th17, lo que se traduce en mayor actividad de estas células. ${ }^{41,42}$ Un ejemplo de activación persistente de la respuesta Th17 se ve en aquellos pacientes que responden a tratamiento con acitretin. Este medicamento reduce la infiltración celular de la epidermis por estos linfocitos e inhibe la proliferación y diferenciación de queratinocitos. Sin embargo, existen genes responsables de la susceptibilidad a este medicamento. Uno de los más importantes es SFRP4, que está disminuido en la piel de los pacientes y su inhibición se relaciona con el aumento de factores de transcripción como Notch y Wnt, implicados en la proliferación y diferenciación celular. El acitretin inhibe ambas vías. ${ }^{43-45}$

4.6. Leishmaniasis: el complejo mayor de histocompatibilidad $(\mathrm{CMH})$ fue estudiado en relación a la respuesta del huésped contra esta enfermedad. En 1991, Lara y su grupo determinaron que algunos HLA clase I y II confieren protección ante la forma localizada de la enfermedad en pacientes venezolanos, específicamente contra Leishmania brasilienzis. Mediante estudios de SNG se determinaron algunos de estos alelos. Se sabe que HLA-Bw22 y HLA-B15 protegen contra la leishmaniasis mientras que HLA-B*07 se asocia con formas difusas. ${ }^{46}$

4.7. Lepra: estudios recientes demostraron que las mitocondrias del huésped juegan un papel crucial en la enfermedad. Por SNG, realizada en biopsias de nervios de pacientes infectados, se detectó que la disminución en la expresión de los genes mitocondriales PARL y PINK1 predispone a un mayor riesgo de padecer la enfermedad. Existe un incremento en el número de copias de los genes mitocondriales LRRK2 y OPA1 en pacientes con lepra lepromatosa, que inhiben al gen PARL, el cual codifica proteínas necesarias para la adecuada función e integridad mitocondrial. ${ }^{47,48}$

4.8. Dermatitis seborreica: se caracteriza por la disrupción de la barrera cutánea, la proliferación y la diferenciación incrementada de queratinocitos y alteraciones en la expresión de genes que codifican citoquinas y lípidos. ${ }^{49}$ Se asocia con levaduras del género Malassezia que forman parte del microbioma normal en la piel sana. El mecanismo a través del cual este organismo desencadena la enfermedad es desconocido. En un estudio realizado por Soares y colaboradores en 2016, se utilizó SNG para cuantificar la cantidad de bacterias y hongos presentes en la flora microbiana de controles sanos y compararla con la de los pacientes. En éstos se detectó una alteración del microbioma a nivel sistémico, con disminución de la flora bacteriana cutánea y aumento considerable de Malassezia que, probablemente, se debe a alteraciones en el sistema inmune, lo que lleva a una disrupción de la barrera cutánea y disbiosis. Este descubrimiento justifica la aplicación de tratamientos sistémicos en casos en los que es difícil lograr remisión completa de la cínica. ${ }^{50}$

4.9. Linfomas cutáneos de células T (LCCT): la presencia de un clon dominante de células $\mathrm{T}$ es una característica de los LCCT. Su sensibilidad y especificidad es limitada porque puede encontrarse este clon en enfermedades benignas mediadas por células $\mathrm{T}$ como liquen plano y pitiriasis liquenoide. En la actualidad, no existe ningún marcador específico para LCCT. En la búsqueda de marcadores para esta enfermedad se determinó mediante SNG que el genoma de los LCCT contiene mutaciones que son secundarias a radiaciones UV. Esto comprueba la teoría del origen a partir de linfocitos $T$ residentes de la piel y no de aquéllos provenientes de nódulos linfáticos regionales. Además, implica que las células de Sézary adquieren marcadores de memoria central y pierden los marcadores de origen cutáneo posterior a la transformación maligna. ${ }^{51}$

En los LCCT pueden encontrarse dos tipos de mutaciones. Oncogenes clásicos como TP53, CDKN2A, KRAS, BRAF, MAK1 y genes de linaje específico que sólo están presentes en neoplasias de células $T$ y alteran su señalización y diferenciación. Uno de los hallazgos más recientes son las mutaciones relacionadas con la hiperactividad del receptor de células T (TCR) en micosis fungoides y síndrome de Sézary. Estas mutaciones pueden ocurrir a cualquier nivel de la vía de señalización del TCR. También pueden producir la inactivación de las señales inhibitorias de dicha vía. Un ejemplo es la alteración por ganancia 
de función de la molécula CD28 que actúa como coestimuladora del TCR. Al existir una mutación, su afinidad por este receptor aumenta y a través de CD86 estimula la producción continua de IL-2 que actúa estimulando la proliferación de $\mathrm{LT}^{52-54}$

En algunos subtipos de LCCT se encontraron deleciones en los genes que codifican para PD-1. La pérdida de autotolerancia es uno de los mecanismos empleados por esta neoplasia y dicha vía podría servir como blanco terapéutico en su tratamiento. Existe un alto porcentaje que presenta mutaciones en la vía del factor de transcripción NF- $\kappa \beta$, por lo que su inhibición con medicamentos como Bortezomib podría ser útil. La vía de JAK-STAT se encuentra también activada en los LCCT. Su inhibición con Tofacitinib y Ruxolitinib ha demostrado resultados eficaces en ensayos clínicos fase 1. ${ }^{55-57}$

4.10. Erupciones medicamentosas: en los últimos años se ha destacado la importancia del sistema inmune en las reacciones adversas a drogas. El desarrollo de métodos de diagnóstico molecular y análisis genómico permitió estudiar el papel de genes que codifican HLA como biomarcadores de predisposición. Mediante SNG se descubrió que la hipersensibilidad a Abacavir está ligada con el HLA-B*57:01 y en pacientes VIH positivo que portan este alelo su detección permitió disminuir la frecuencia de erupciones medicamentosas. A partir de este primer estudio se realizaron asociaciones de HLA con otros medicamentos y se encontró que tanto el Alopurinol como la Carbamazepina se relacionan con alelos que determinan la susceptibilidad a estas drogas (HLAB*58:01 y HLA-B*1502/HLA-A*3101, respectivamente). En la actualidad se están desarrollando paneles de genes que se relacionan con hipersensibilidad a fármacos para identificar a pacientes en riesgo. ${ }^{58,59}$

\section{REFERENCIAS}

1. National Human Genome Research Institute. An overview of the Human Genome Project [Internet]. 2016 [citado 1 de julio de 2017]. Disponible en: https://www.genome.gov/12011238/ an-overview-of-the-human-genome-project/

2. National Human Genome Research Institute. DNA sequencing fact sheet [Internet]. 2015 [citado 1 de julio de 2017]. Disponible en: https://www.genome.gov/10001177/dna-sequencing-fact-sheet/.

3. National Human Genome Research Institute. Human Genome Project completion: frequently asked questions [Internet]. 2010 [citado 1 de julio de 2017]. Disponible en: https://www.genome. gov/11006943/human-genome-project-completion-frequentlyasked-questions/.

4. Khan Academy. DNA sequencing [Internet]. 2015 [citado 30 de junio de 2017]. Disponible en: https://www.khanacademy.org/ science/biology/biotech-dna-technology/dna-sequencing-pcrelectrophoresis/a/dna-sequencing

5. Shendure J, Ji H. Next-generation DNA sequencing. Nat Biotechnol. 2008; 26 (10): 1135-1145.

6. Garrido-Cardenas JA, Garcia-Maroto F, Álvarez-Bermejo JA, Manzano-Agugliaro F. DNA sequencing sensors: an overview. Sensors. 2017; 17 (588): 1-15.

7. Bitesize Bio. Beginner's Guide to Next Generation SequencingBitesize Bio [Internet]. 2014 [citado 29 de junio de 2017]. Disponible en: http://bitesizebio.com/21193/a-beginners-guideto-next-generation-sequencing-ngs-technology/.

8. Behjati S, Tarpey PS. What is next generation sequencing? Arch Dis Child Educ Pr Ed. 2013;98: 236-238.

9. Sarig O, Sprecher E. The molecular revolution in cutaneous biology: era of next-generation sequencing. J Invest Dermatol. 2017; 137 (5): 79-82.
10. Mellmann A, Harmsen D, Cummings CA, Zentz EB, Leopold $\mathrm{SR}$, Rico A et al. Prospective genomic characterization of the german enterohemorrhagic Escherichia coli O104: H4 outbreak by rapid next generation sequencing technology. PLoS One. 2011; 6 (7) :e22751.

11. Buermans HPJ, Dunnen JT Den. Biochimica et Biophysica acta next generation sequencing technology: advances and applications. BBA-Mol Basis Dis [Internet]. 2014; 1842 (10): 1932-1941. Disponible en: http://dx.doi.org/10.1016/j. bbadis.2014.06.015.

12. Shen T, Stadt SHP De, Yeat NC, Lin JC. Clinical applications of next generation sequencing in cancer: from panels, to exomes, to genomes. Front Genet. 2015; 6: 1-9.

13. Titeux M, Izmiryan A, Hovnanian A. The molecular revolution in cutaneous biology: emerging landscape in genomic dermatology: new mechanistic ideas, gene editing, and therapeutic breakthroughs. J Invest Dermatol [Internet]. 2016; 137 (5): 123-129. Disponible en: http://dx.doi.org/10.1016/j.jid.2016.08.038.

14. Anbunathan $\mathrm{H}$, Bowcock AM. The molecular revolution in cutaneous biology: the era of genome-wide association studies and statistical, big data, and computational topics. J Invest Dermatol [Internet]. 2016; 137 (5): 113-118. Disponible en: http:// dx.doi.org/10.1016/j.jid.2016.03.047.

15. Mcgrath JA. The molecular revolution in cutaneous biology: era of molecular diagnostics for inherited skin diseases. J Immunol [Internet]. 2017; 137 (5): 83-86. Disponible en: http://dx.doi. org/10.1016/j.jid.2016.02.819.

16. Takeichi T, Nanda A, Liu L, Salam A, Campbell P, Fong K et al. Impact of next generation sequencing on diagnostics in a genetic skin disease clinic. Exp Dermatol. 2013; 22 (1): 825-831. 
17. Has C, Küsel J, Reimer A, Hoffmann J, Schauer F, Zimmer $A$. The position of targeted next-generation sequencing in epidermolysis bullosa diagnosis. Acta Derm Veneorol. 2018; 98: 437-440.

18. Rajkumar S, Watson IR. Molecular characterisation of cutaneous melanoma: creating a framework for targeted and immune therapies. Br J Cancer [Internet]. 2016; 115 (2): 145-155. Disponible en: http://dx.doi.org/10.1038/bjc.2016.195.

19. Richtig G, Hoeller C, Kashofer K, Aigelsreiter A, Heinemann A, Kwong LN et al. Beyond the BRAFV600E hotspot-Biology and clinical implications of rare BRAF gene mutations in melanoma patients. Br J Dermatol. 2017; 177 (4): 936-944.

20. Serratì $S$, Petriella D. Next-generation sequencing: advances and applications in cancer diagnosis. Onco Targ Ther. 2016; 9: 7355-7365.

21. Carlson JA, Candido J, Xavier C, Tarasen A, Sheehan CE, Otto $G$ et al. Next-generation sequencing reveals pathway activations and new routes to targeted therapies in cutaneous metastatic melanoma. Am J Dermatopathol. 2017; 39 (1): 1-13.

22. Reiman A, Kikuchi $H$, Scocchia D, Smith $P$, Tsang YW, Snead $D$ et al. Validation of an NGS mutation detection panel for melanoma. BMC Cancer. 2017; 17 (50): 1-7.

23. Bustos BDU, Estal RM, Simó GP, Juan I De, Muñoz BE, Serna MR et al. Towards personalized medicine in melanoma: implementation of a clinical next-generation sequencing panel. Sci Rep. 2017; 7 (495): 1-11.

24. Siroy AE, Boland GM, Milton DR, Roszik J, Frankian S, Malke $\mathrm{J}$ et al. Beyond BRAFV600: clinical mutation panel testing by next-generation sequencing in advanced melanoma. J Invest Dermatol. 2015; 135 (2): 508-515.

25. Gandolfi G, Dallaglio K, Longo C, Moscarella E, Lallas A, Alfano R. Contemporary and potential future molecular diagnosis of melanoma. Expert Rev Mol Diagn. 2016; 16 (9): 975-985.

26. Griewank KG, Schilling B. Next-generation sequencing to guide treatment of advanced melanoma. Am J Clin Dermatol. 2017; 18 (3): 303-310.

27. Levesque MP, Cheng PF, Raaijmakers MIG, Saltari A, Dummer R. Metastatic melanoma moves on: translational science in the era of personalized medicine. Cancer Met Rev. 2017; 36 (1): $7-21$.

28. Cosgarea I, Ugurel S, Sucker A, Livingstone E, Hillen U, Horn $S$ et al. Targeted next generation sequencing of mucosal melanomas identifies frequent NF1 and RAS mutations. Oncotarget. 2017; 8 (25): 40683-40692.

29. Johnson DB, Frampton GM, Rioth MJ, Yusko E, Xu Y, Guo X et al. Targeted next generation sequencing identifies markers of response to PD-1 blockade. Cancer Immunol Res. 2016; 4 (11): 959-968.

30. Reddy BY, Miller DM, Tsao H. Somatic driver mutations in melanoma. Cancer. 2017; 123 (S11): 2104-2117.

31. Badal B, Solovyov A, Cecilia S Di, Chan JM, Chang L, Iqbal R, et al. Transcriptional dissection of melanoma identifies a highrisk subtype underlying TP53 family genes and epigenome deregulation. JCl Insight. 2017; 2 (8): 1-15.

32. Faden DL, Arron ST, Heaton CM, Derisi J, South AP, Wang SJ. Targeted next-generation sequencing of TP53 in oral tongue carcinoma from non- smokers. J Otolaryngol Head Neck Surg [Internet]. 2016; 45 (1): 45-47. Disponible en: http://dx.doi. org/10.1186/s40463-016-0160-4.

33. Ikeda S, Goodman AM, Cohen PR, Jensen TJ, Ellison CK, Frampton $G$ et al. Metastatic basal cell carcinoma with amplification of PD-L1: exceptional response to anti-PD1 therapy. NPJ Genom Med. 2016; Epub 2016: 1-12.
34. Kita R, Fraser HB. Local adaptation of sun-exposure-dependent gene expression regulation in human skin. PLoS Genet. 2016; 12 (10): 1-18.

35. Sand M, Bechara FG, Gambichler T, Sand D, Friedländer R, Bromba $M$ et al. Next generation sequencing of the basal cell carcinoma miRNome and a description of novel microRNA candidates under neoadjuvant vismodegib therapy: an integrative molecular and surgical case study. Ann Oncol. 2016; 27 (2): 332-338.

36. Al-rohil RN, Tarasen AJ, Carlson JA, Wang K, Johnson A, Yelensky $R$ et al. Evaluation of 122 advanced-stage cutaneous squamous cell carcinomas by comprehensive genomic profiling opens the door for new routes to targeted therapies. Cancer. 2016; 122 (2): 249-257.

37. Ganzenmueller T, Yakushko Y, Kluba J, Henke-Gendo C, Gutzmer R, Schulz TF. Next-generation sequencing fails to identify human virus sequences in cutaneous squamous cell carcinoma. Int J Cancer. 2012; 131 (7): E1173-1179.

38. Ganzenmueller T, Hage E, Yakushko Y, Kluba J, Woltemate $\mathrm{S}$, Schacht $\mathrm{V}$ et al. No human virus sequences detected by next-generation sequencing in benign verrucous skin tumors occurring in BRAF-inhibitor-treated patients. Exp Dermatol. 2013; 22 (16): 725-729.

39. Mroz EA, Rocco JW. Intra-tumor heterogeneity in head and neck cancer and its clinical implications. J Otolaryngol Head Neck Surg [Internet]. 2016; 2 (2): 60-67. Disponible en: http://dx.doi. org/10.1016/j.wjorl.2016.05.007.

40. Tanese K, Nakamura Y, Hirai I, Funakoshi T. Updates on the systemic treatment of advanced non-melanoma skin cancer. Front Med. 2019; 6: 1-10.

41. Cao X, Wa Q, Wang Q, Li L, Liu X, An L et al. International immunopharmacology high throughput sequencing reveals the diversity of TRB-CDR3 repertoire in patients with psoriasis vulgaris. Int Immunopharmacol. 2016; 40 (2016): 487-491.

42. Castelino M, Eyre S, Moat J, Fox G, Martin P, Ho P et al. Optimisation of methods for bacterial skin microbiome investigation?: primer selection and comparison of the 454 versus MiSeq platform. BMC Microbiol [Internet]. 2017; 17 (23): 1-12. Disponible en: http://dx.doi.org/10.1186/s12866-017-0927-4.

43. Zhou X, He Y, Kuang Y, Li J, Zhang J, Chen M et al. Whole exome sequencing in psoriasis patients contributes to studies of acitretin treatment difference. Int J Mol Sci. 2017;18(295):1-11.

44. Joyce CE, Zhou X, Xia J, Ryan C, Thrash B, Menter A et al. Deep sequencing of small RNAs from human skin reveals major alterations in the psoriasis miRNAome. Hum Mol Gen. 2011; 20 (20): 4025-4040.

45. Li B, Tsoi LC, Swindell WR, Gudjonsson JE, Johnston A, Ding J, et al. Transcriptome analysis of psoriasis in a large case-control sample: RNA-seq provides insights into disease mechanisms. J Invest Dermatol. 2015; 134 (7): 1828-1838.

46. Samaranayake N, Fernando SD, Neththikumara NF, Rodrigo C, Karunaweera ND, Dissanayake VHW. Association of HLA class I and II genes with cutaneous leishmaniasis?: a case control study from Sri Lanka and a systematic review. BMC Infect Dis [Internet]. 2016; 16 (292): 1-9. Disponible en: http://dx.doi. org/10.1186/s12879-016-1626-8.

47. Benjak A, Singh P, Pontes MAA, Gonc HS, Silveira MIS, Cruz R et al. Whole genome sequencing distinguishes between relapse and reinfection in recurrent leprosy cases. PLoS Negl Trop Dis. 2017; 11 (6): 1-13.

48. Wang D, Zhang D, Feng J, Li G, Li X, Yu X. Common variants in the PARL and PINK1 genes increase the risk to leprosy in Han Chinese from South China. Sci Rep. 2016; 23 (6): 1-9. 
49. Soares RC, Camargo-penna PH, Moraes VCS De. Dysbiotic bacterial and fungal communities not restricted to clinically Affected Skin Sites in Dandruff. Front Cell Infect Microbiol. 2016; 6 (157): 1-10.

50. Park M, Yang YC, Lee W, Jung WH. Whole genome sequencing analysis of the cutaneous pathogenic yeast Malassezia restricta and identification of the major lipase expressed on the scalp of patients with dandruff. Mycoses. 2017; 60 (3): 188-197.

51. Weng W, Weng W, Armstrong R, Arai S, Desmarais C, Hoppe R et al. Minimal residual disease monitoring with high-throughput sequencing of $\mathrm{T}$ cell receptors in cutaneous $\mathrm{T}$ cell lymphoma. Sci Transl Med. 2013; 171 (5): 1-9.

52. Damsky WE, Choi J. Genetics of cutaneous T cell lymphoma: from bench to bedside. Curr Treat Options Oncol [Internet]. 2016; 17 (33): 1-14. Disponible en: http://dx.doi.org/10.1007/ s11864-016-0410-8.

53. Sufficool KE, Lockwood CM, Abel HJ, Hagemann IS, Schumacher JA, Kelley TW et al. T-cell clonality assessment by next-generation sequencing improves detection sensitivity in mycosis fungoides. J Am Dermatology [Internet]. 2015; 73 (2): 228-236. Disponible en: http://dx.doi.org/10.1016/j. jaad.2015.04.030
54. Mcgirt LY, Jia P, Baerenwald DA, Duszynski RJ, Dahlman KB, Zic JA et al. Whole-genome sequencing reveals oncogenic mutations in mycosis fungoides. Blood. 2015; 126 (4): 508-520.

55. Iżykowska K, Przybylski GK, Gand C, Braun FC, Grabarczyk P, Kuss AW et al. Genetic rearrangements result in altered gene expression and novel fusion transcripts in Sézary syndrome. Oncotarget. 2017; 8 (24): 39627-39639.

56. Chevret E, Merlio J. Sézary Syndrome: translating genetic diversity into personalized medicine. J Invest Dermatol [Internet]. 2016; 136 (7): 1319-1324. Disponible en: http://dx.doi. org/10.1016/j.jid.2016.04.027.

57. Wang L, Ni X, Covington KR, Yang BY, Shiu J, Zhang X, et al. Genomic profiling of Sézary Syndrome identifies alterations of key T-cell signaling and differentiation genes Linghua. Nat Genet. 2016; 47 (12): 1426-1434.

58. Maekawa K, Nishikawa J, Kaniwa N, Sugiyama E, Koizumi T. Development of a rapid and inexpensive assay for detecting a surrogate genetic polymorphism of HLA-B*58:01: a partially predictive but useful biomarker for allopurinol-related StevensJohnson Syndrome/toxic epidermal necrolysis in Japanese. Drug Metab Pharmacokinet. 2012; 27 (4): 447-450.

59. Pirmohamed M. Genetics and the potential for predictive tests in adverse drug reactions. Chem Immunol Allergy. 2012; 97: 18-31. 